\title{
TAKING OUT THE TRASH (AND THE RECYCLABLES): RFID AND THE HANDLING OF MUNICIPAL SOLID WASTE
}

\author{
David C. Wyld ${ }^{1}$ \\ ${ }^{1}$ Department of Management, Southeastern Louisiana University, Hammond, LA USA \\ dwyldeselu.edu
}

\begin{abstract}
This article examines how RFID (radio frequency identification) is poised to help transform the way we handle our trash - our MSW (Municipal Solid Waste). We provide an overview showing that trash trends in the United States are not good, as modern life has meant increasing volumes of trash that can be disposed of in fewer and fewer landfills. We examine how RFID can be employed in the MSW area to both facilitate the growth of PAYT (Pay as You Throw) use-based billing for waste management services and to promote incentive-based recycling programs, both of which aim to reduce the amount of trash entering our landfills. We discuss the prospects for the future as RFID is introduced into what is now a $\$ 52$ billion market for waste handling.
\end{abstract}

\section{KEYWORDS}

RFID (radio frequency identification) technology, MSW (Municipal Solid Waste), Waste Management, Recycling, Environment, Business Intelligence

\section{INTRODUCTION}

Modern life has become much more complicated....and trashy! Every empty coffee cup, box of cereal, tissue, cracked CD case, etc. adds-up. In fact, according to the most recent data available from the U.S. Environmental Protection Agency (EPA), every American man, woman and child produces - on average - in excess of four and a half pounds of trash (formally referred to as Municipal Solid Waste [MSW]). As can be seen Figure 1, this represents an over $75 \%$ increase over the per capita amount generated in 1960 and a 50\% increase over that found in 1980 [1].

While the per capita rate has somewhat stabilized over the past two decades, the problem is that with an ever-increasing population, the cumulative volume of MSW is rapidly expanding. As can be seen in Figure 2, Americans produce a staggering 254 billion tons of trash each year. This represents an approximate $300 \%$ increase over the past 50 years [1]! And, to complicate matters even further, due to a wide range of economic, political and environmental factors, the number of landfills for all this "stuff" to be reposited into has markedly declined. In fact, as can be seen in Figure 3, according to the EPA [1], today there are less than a quarter of the total number of landfills than were available in the U.S. just two decades ago - down from just under 8,000 in 1988 to 1,754 in 2007 ! The shortage of landfill space is contributing to an escalation in "tipping fees" - the fees landfills charge to receive a ton of MSW - which range between $\$ 10$ and $\$ 30$ per ton in most parts of the country [2]. There are already severe shortages of landfill space in pockets of the country. In fact, six states - Alaska, Connecticut, Delaware, North Carolina, New Hampshire and Rhode Island - have less than five years of landfill capacity remaining 


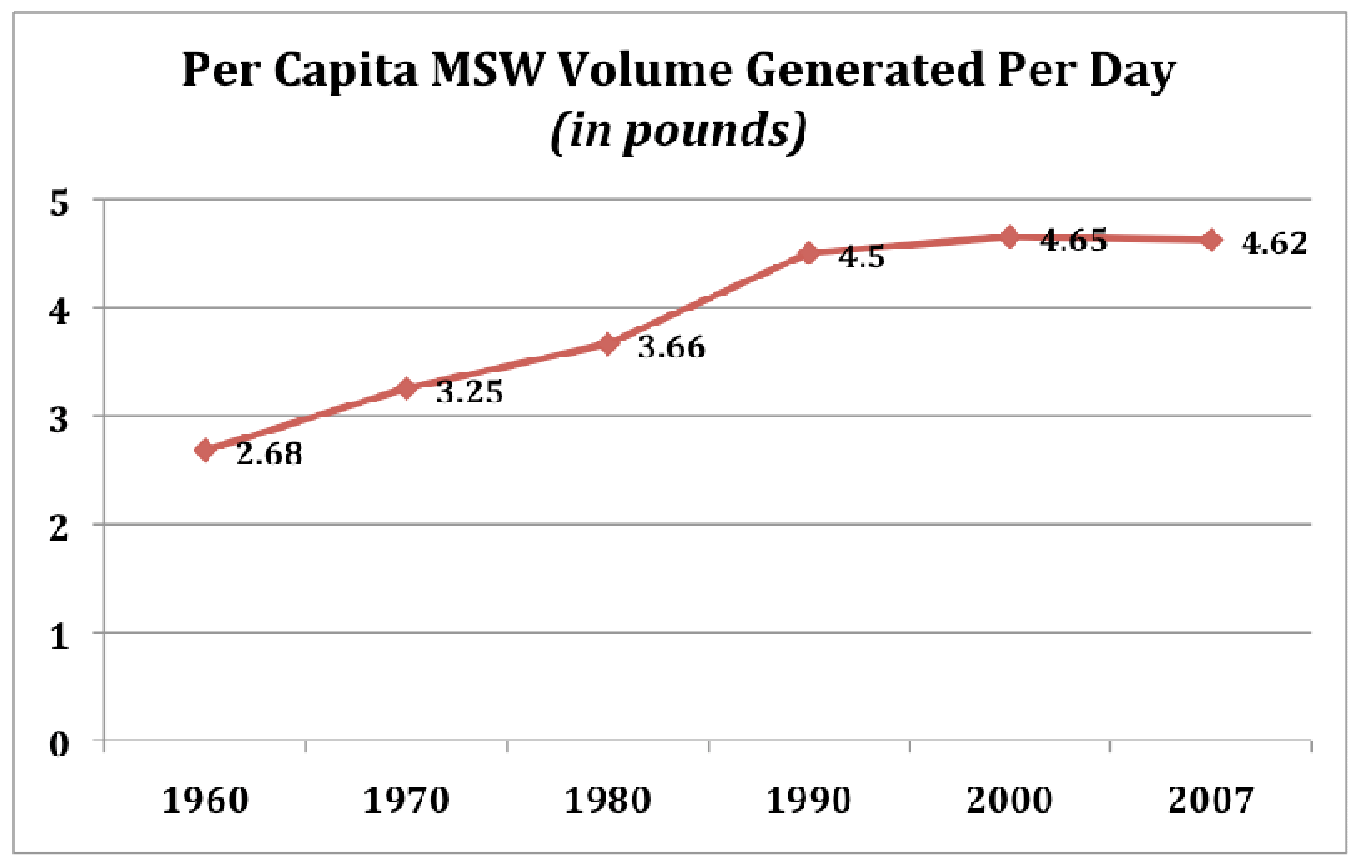

Figure 1. The Rise in Individual Trash Generation, 1960-2007 [1]

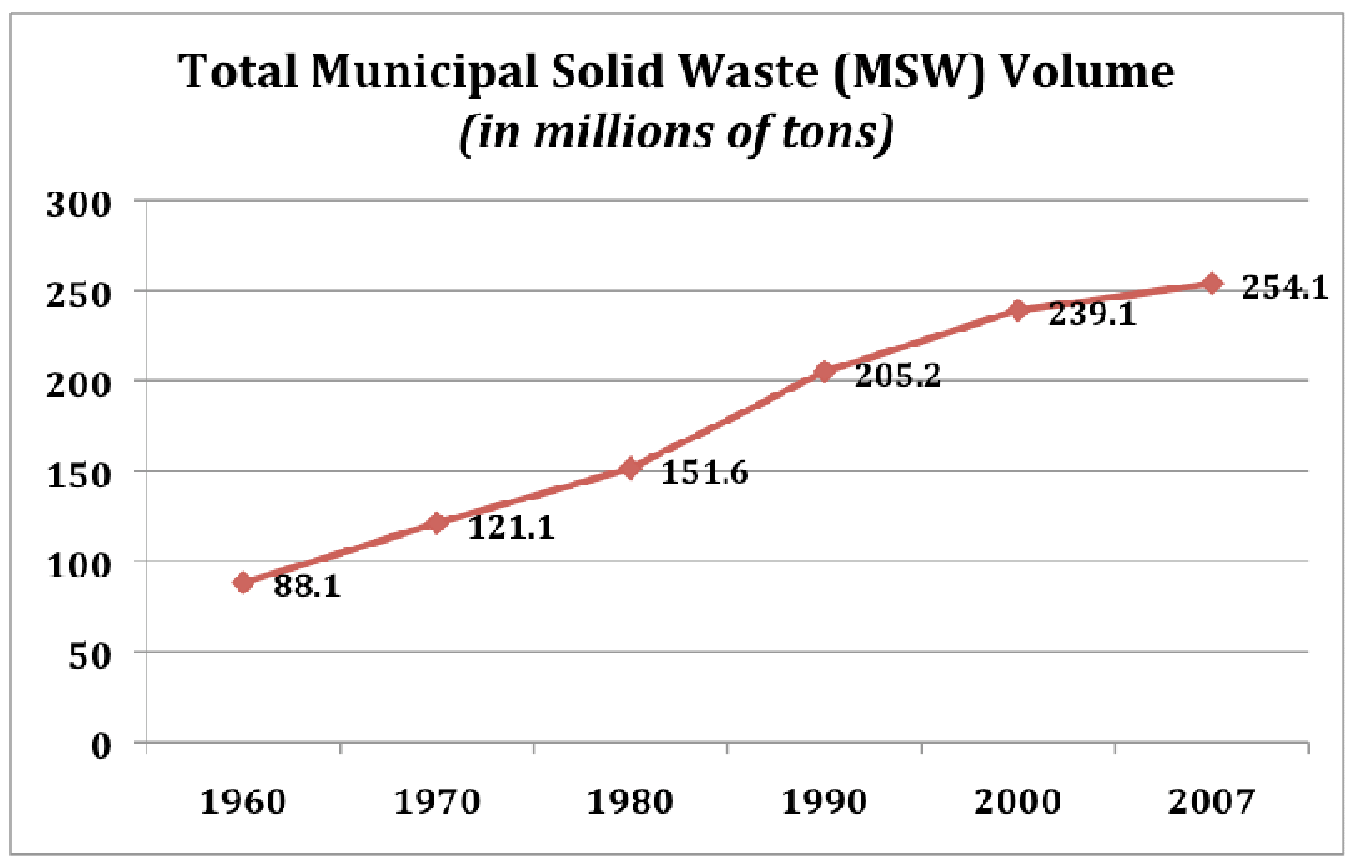

Figure 2. The Rise in Overall Trash Generation, 1960-2007 [1]

[3]. In these states, and throughout the Northeast part of the United States, tipping fees have crept much higher, ranging today between $\$ 45$ and $\$ 85$ per ton [4]. 


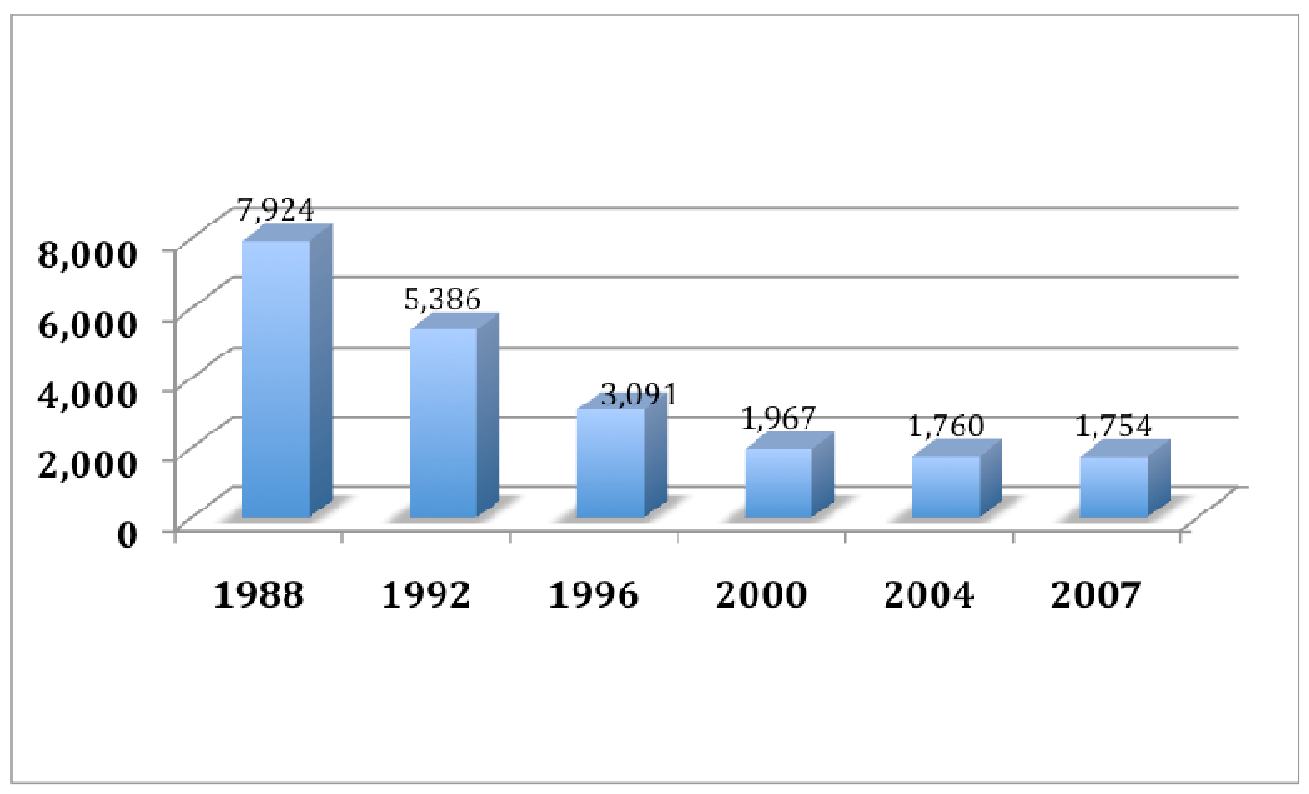

Figure 3. Total Number of Landfills in the United States, 1988-2007 [1]

Undoubtedly, the business of "trash" - or Municipal Solid Waste (MSW) - is an increasingly important one. It is also an exceedingly complex business, as firms engaged in handling MSW must comply with a panoply of environmental rules and regulations, which adds significantly to their operating costs [5]. Furthermore, there is actually - for lack of a better term - a "trash reverse supply chain" that begins when we place our household waste in a garbage bag, can or dumpster. Our trash is joined with that of other households and apartment dwellers in the local hauling trash trucks we see on our streets. Yet, with local landfills either being closed or fastreaching their capacities, today it is increasingly common that the trash we throw out at our curbside will be loaded onto larger trucks and offloaded at transfer stations, perhaps several times, before reaching its final resting place at one of the increasingly large "superlandfills" [6]. All of this means that the business of handling, transporting and processing MSW is becoming a more complex and more expensive logistical operation [7], and all signs point to no an increasingly difficult operating environment for waste management companies. Less trash to handle would significantly help the proposition.

While the trash business is an area that many would perceive as a stodgy, low-tech, low-growth business, it is one where RFID (radio frequency identification) presents some intriguing possibilities for waste management. This article first provides an overview of RFID technology. Then, we analyze how RFID can reinvent the business model for waste handling through innovative applications of auto-ID technology, revolutionizing the way municipalities and contractors bill for trash collection, and in the process, the manner in which all of us regard "trash." In the process, RFID holds the potential for dramatically reducing the volume of trash and increasing the amount of material being recycled. In the latter regard, RFID can - for the first time - offer real incentives for individuals to participate in recycling programs from their own homes, helping the environment and their communities - and their pocketbooks as well. 


\section{RFID 101}

\subsection{Automatic Identification}

Automatic Identification, or Auto-ID, represents a broad category of technologies that are used to help machines identify objects, humans, or animals. As such, it is often referred to as automatic data capture, as Auto-ID is a means of identifying items and gathering data on them without human intervention or data entry. Like the omnipresent bar code, RFID is fundamentally another form of Auto-ID technology - "a wireless link to identify people or objects" [8]. RFID is thus, in reality, a subset of the larger radio frequency (RF) market, with the wider market encompassing an array of RF technologies, including:

- cellular phones,

$\circ$ digital radio,

○ the Global Positioning System (GPS),

- High-Definition Television (HDTV), and

○ wireless networks [9].

RFID is by no means a "new" technology - as it dates back to World War II [10]. In fact, it is a technology that already surrounds us. First off, if you have an automobile that was manufactured after 1994, the car uses RFID to verify that it is your key in the ignition. Otherwise, the car won't start. If you have an Exxon/Mobil SpeedPass ${ }^{\mathrm{TM}}$ in your pocket, you're using RFID. If you have a toll tag on your car, you're using RFID. If you have checked out a library book, you've likely encountered RFID. If you've been shopping in a department store or an electronics retailer, you've most certainly encountered RFID in the form of an EAS (Electronic Article Surveillance) tag.

\subsection{RFID and Bar Codes}

Conceptually, bar codes and RFID are indeed quite similar, as both are auto-ID technologies intended to provide rapid and reliable item identification and tracking capabilities. The primary difference between the two technologies is the way in which they "read" objects. With bar coding, the reading device scans a printed label with optical laser or imaging technology. However, with RFID, the reading device scans, or interrogates, a tag using radio frequency signals.

The specific differences between bar code technology and RFID are summarized in Table 1. In summary however, there are five primary advantages that RFID has over bar codes. These are:

1. Each RFID tag can have a unique code that ultimately allows every tagged item to be individually accounted for,

2. RFID allows for information to be read by radio waves from a tag, without requiring line of sight scanning or human intervention,

3. RFID allows for virtually simultaneous and instantaneous reading of multiple tags, 
4. RFID tags can hold far greater amounts of information, which can be updated, and

5. RFID tags are far more durable [10].

Table 1. RFID and Bar Codes Compared

\begin{tabular}{|c|c|}
\hline Bar Code Technology & RFID Technology \\
\hline $\begin{array}{l}\text { - Bar Codes require line of sight to be } \\
\text { read }\end{array}$ & $\begin{array}{l}\text { - RFID tags can be read or updated } \\
\text { without line of sight }\end{array}$ \\
\hline $\begin{array}{l}\text { - Bar Codes can only be read } \\
\text { individually }\end{array}$ & $\begin{array}{l}\text { - Multiple RFID tags can be read } \\
\text { simultaneously }\end{array}$ \\
\hline $\begin{array}{l}\text { - Bar Codes cannot be read if they } \\
\text { become dirty or damaged }\end{array}$ & $\begin{array}{l}\text { - RFID tags are able to cope with harsh } \\
\text { and dirty environments }\end{array}$ \\
\hline $\begin{array}{l}\text { - Bar Codes must be visible to be } \\
\text { logged }\end{array}$ & $\begin{array}{l}\text { - RFID tags are ultra thin and can be } \\
\text { printed on a label, and they can be } \\
\text { read even when concealed within an } \\
\text { item }\end{array}$ \\
\hline $\begin{array}{l}\text { - Bar Codes can only identify the type } \\
\text { of item }\end{array}$ & - RFID tags can identify a specific item \\
\hline $\begin{array}{l}\text { - Bar Code information cannot be } \\
\text { updated }\end{array}$ & $\begin{array}{l}\text { - Electronic information can be over- } \\
\text { written repeatedly on RFID tags }\end{array}$ \\
\hline $\begin{array}{l}\text { - Bar Codes must be manually tracked } \\
\text { for item identification, making human } \\
\text { error an issue }\end{array}$ & $\begin{array}{l}\text { - RFID tags can be automatically } \\
\text { tracked, eliminating human error }\end{array}$ \\
\hline
\end{tabular}

\subsection{How RFID Works}

There are three necessary elements for an RFID system to work. These are tags, readers, and the software necessary to link the RFID components to a larger information processing system. In brief, the science of a passive RFID system works like this. The RFID tag is the unique identifier for the item it is attached to. The reader sends out electromagnetic waves, and a magnetic field is formed when the signal from the reader "couples" with the tag's antenna. The unpowered RFID tag draws its power from this magnetic field, and it is this power that enables the tag to send back an identifying response to the query of the RFID reader. When the power to the silicon chip on the tag meets the minimum voltage threshold required to "turn it on," the tag then can respond to the reader through the same radio frequency (RF) wave. The reader then converts the tag's response into digital data, which the reader then sends on to the information processing system to be used in management applications. Writing in Wired, Singel [11] likened passive RFID to a "high-tech version of the children's game "Marco Polo"" (n.p.). In a passive RFID system, the reader sends out a signal on a designated frequency, querying if any tags are present in its read filed (the equivalent of yelling out "Marco" in a swimming pool). If a chip is present, the tag takes the radio energy sent-out by the reader to power-it-up and respond with the electronic equivalent of kids yelling "Polo" when they are found.

All of this happens almost instantaneously. In fact, today's RFID readers are capable of reading tags at a rate of up to 1,000 tags per second. Through a process known as "simultaneous identification," most RFID systems can capture data from many tags within range of the reader's antenna almost simultaneously. In reality however, the tags are responding individually - within milliseconds of one another - in a manner to prevent tag and reader collision in their signals through response protocols [10]. 


\subsection{Analysis}

While it will take a few years for RFID to become commonplace on retail store shelves and the store of the future to become a reality, RFID is already being used in a wide variety of creative applications, including:

- A worker at a distribution center can instantly identify each and every one of the items contained in every box on a pallet on the tongs of the forklift she is driving;

- A librarian can locate a book that had been hopelessly misshelved;

- A worker at a livestock processing facility can instantly access the identity and history of a cow;

- A hospital can locate critical medical devices instantly, wherever they are located throughout the facility;

- A blood bank can track its inventory with greater accuracy;

- A pharmacist can tell that two bottles in his supply of a high in demand, highly addictive prescription drug are counterfeit;

- A military contractor can instantly locate the necessary spare to repair a Blackhawk helicopter;

- An art museum can use RFID-enabled exhibits to provide enhanced visitor experiences by making exhibits come "alive"; and yes,

- A golfer can instantly locate his errant shot and retrieve the ball from the thicket where it landed.

Futurist Paul Saffo foresees that much of the focus on RFID today is on doing old things in new ways, but the truly exciting proposition is the new ideas and new ways of doing things that will come from RFID. He predicts that: "RFID will make possible new companies that do things we don't even dream about" [12]. As such, this new, old technology will become one of the driving forces of the $21^{\text {st }}$ century. RFID is thus an exciting technology, one that is poised to enter our lives in many exciting ways over the next decade. The ability of RFID to deliver rich information, instantaneously and automatically, is why major retailers in the U.S. and abroad, including Wal-Mart, Target, Metro, and Tesco, along with the U.S. Department of Defense, are major backers of employing the technology in their supply chains [13]. And, while much of the media and investment focus has been on such warehousing and retailing applications, now, there is increased interest in applying RFID in a wide variety of settings, including health care $[14,15,16]$, sports and entertainment [17], museums and theme parks [18], and yes, casinos [19].

\section{RFID AND WASTE/RECYCLING}

\subsection{The Municipal Solid Waste Marketplace}


Traditionally in the United States, trash collection has been a service performed by municipal governments - for a flat fee -for its citizens [20]. Today, cities largely contract out for the service, leading to the rise of several large national firms that dominate the America market, including Waste Management, Allied Waste, BFI, and Republic Services, as well as myriad small local firms that compete as well in this $\$ 52$ billion annual marketplace [21]. Due to the necessity for such services and the steady cash flow from the monthly billing in this fixed price business model, trash collection is a financially steady and attractive - if sometimes smelly market for waste management service providers.

However, the single rate model has been criticized not just by environmentalists, but by the federal Environmental Protection Agency as well. The flat rate system provides no incentive for individuals to reduce the amount of waste they put out for collection. As such, heavy users pay the same as light users, making it not only inequitable, but actually harmful to the environment. This is because the flat rate pricing provides no incentive for individuals to participate in recycling programs, encourage composting, or to choose to use source reduction products and packaging [22]. In response, some communities have went to hybrid models, charging citizens a flat base rate for a single trash container and then charging a variable rate for additional garbage collection [23], much akin to the model being pursued today with airlines charging more for a second, third, fourth, etc. bag [24]. Research has shown that some economic disincentives impact individual trash behavior by influencing their cost-benefit calculus by making more trash more expensive [25].

\subsection{Pay As You Throw}

There is growing support for a radically different pricing model in the trash business today, known as "Pay As You Throw" (PAYT). Under the PAYT model, people pay a variable rate, based on the amount of trash they actually put out to be collected by the waste management contractor [22]. Over 6,0000 American cities, as well as many cities across Europe and Australia, currently have PAYT systems. In fact, some have been in place for decades [26]. However, in the past, such systems have been based on homeowners buying stickers for each garbage can or purchasing specially authorized and/or labeled trash bags, "paying" for each container in which they could "throw" their trash away [27]. Such long-standing PAYT systems have not gone without issues, including residents intentionally depositing their trash in other people's containers (to avoid their own charges) and a limited rise in the illegal dumping or burning of trash in remote areas [28]. It has also brought about what industry experts have termed the "Seattle stomp" phenomenon. This trend was labeled as such because residents in Seattle, Washington and other unit pricing cities commonly compact their trash, trying to beat the per-container pricing system by compacting huge amounts of trash into a single can or bag (reducing their trash output by volume, but not by weight) [29]. All in all however, Pay As You Throw has been shown to have an impact on households' "trash behavior," significantly decreasing trash output by both weight and volume, while increasing the portion of their waste that was diverted to recycling [30].

Now, RFID technology is being introduced into the waste management industry, making the PAYT model workable. Texas Instruments has been a leading proponent of using auto-ID technology to not just better the business intelligence of waste management contractors (enabling them to monitor their fleets and worker performance, both for optimizing routing and quality assurance, especially when combined with GPS that is already in wide use in the industry) [31]. TI has also demonstrated the workability of PAYT in the field. The key is RFIDenabling individual trash containers. Specially-equipped garbage trucks can then weigh each "smart" trash can upon collection, making it possible to ascertain the "net amount" of garbage collected from each customer each time each customer's trash is gathered. The collection process can remain unchanged from what it is today, as the weighing is done as the can is lifted 
and emptied into the trash truck by the operator, thereby not slowing down the present system performance [32]. Texas Instruments' tests have made use of low frequency RFID tags, due to the harsh environment and the omnipresence of both water (in the content of MSW) and metal (in the trash truck and with metal trash cans in many instances) [31]. Further, in many urban and even suburban settings, such as apartment buildings, multiple trash cans are in close enough proximity where there would be great potential for misreads and tag collision/confusion.

Whether or not RFID-enhanced PAYT would prove to be revenue enhancing, neutral or negative overall for cities and their waste management contractors remains to be seen. The accuracy possible through the use of automatic identification technology does make possible new concepts for individual accountability and tracking. However, the PAYT concept certainly encourages more individual environmental responsibility when it comes to household management of MSW. The one thing that is assured is that it does encourage folks to recycle what can recycled from their own trash, decreasing their net trash output and thus, their weightbased trash charges. With RFID making it more possible to accurately assess weight and volume-based trash charges for each customer, this will yield more recycling incentives than ever. And now, RFID is being brought to bear to directly encourage recycling through tracking and "incentivizing" the process for individuals.

\subsection{Growing Recycling}

According to the most recent data available (for the 2007 calendar year), the EPA found that just over a third of all Municipal Solid Waste in the United States is actually recycled. With only about $12 \%$ of all MSW is burned for energy recovery or simply incinerated, this means that over half of our total trash output - 54\% - still ends-up simply reposited into ever-fewer landfills [1]. Paper and paperboard is the largest category of our trash output, comprising almost a third of the total. Yet, as can be seen in Figure 4, barely half (54.5\%) of our paper products are actually recycled. In fact, the EPA data shows that recycling rates overall lag expectations [1].

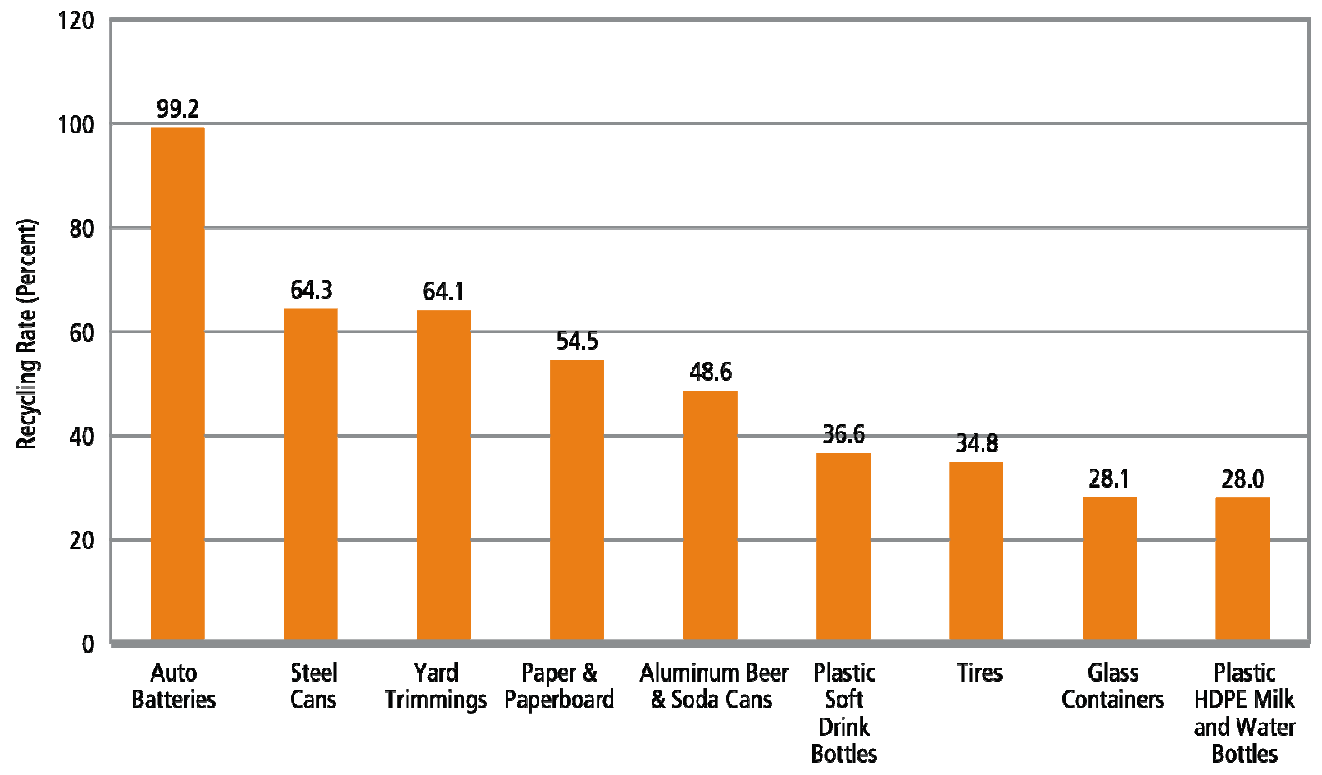

Figure 4. Recycling Rates of Selected Products, 2007 [1]

Why does participation in recycling efforts lag? Analysts often point to cumbersome recycling requirements imposed by cities and their waste contractors [33]. Such program requirements 
require citizens to not just separate their recyclables by product category, but ask them to put specific items out for pick-up on specific days (i.e. glass on Mondays, paper on Wednesdays, plastics on Fridays) or to take the items to recycling collection centers, rather than setting the items out with their "normal" trash on their "normal" collection days.

Today, innovative recycling solutions providers are looking to use RFID to make recycling "easier" and to track the recycling patterns of individual households. Some are even finding a way to "incentivize" individuals into recycling behavior by not just reducing their PAYT garbage bills, but actually paying or rebating them directly for the amount of recyclabes they divert from the landfill. There are several firms vying for this market, including RecycleBank (http://www.recyclebank.com/), based in New York City, Routeware (http://www.routeware.com/), based in Beaverton, Oregon, and an Irish firm, Advanced Manufacturing Control Systems (AMCS) (http://www.amcs.ie/). Austin Ryan, cofounder and business development director for AMCS, recently commented that: "Increasing recycling rates requires the deployment of creative new strategies and technologies in the waste management industry" [34]. Each of these firms are marketing solutions whereby the recycling collection process makes use of special RFID-tagged recycling containers (using low-frequency RFID tags), which are collected by trucks equipped with smart scales that read the tags (to associate the collection with a particular customer) and to weigh that customer's recyclables (based on the weight of the filled container versus the empty container weight) $[34,35]$.

For example, RecycleBank currently serves a number of cities - (the largest of which is Philadelphia) in the Northeast, covering several hundred thousand homes. RecycleBank's system works in tandem with existing municipal waste management contractors' collections, as they do not operate their own collection equipment. They do provide customers with RFIDequipped recycling carts, ranging between 35-96 gallons in size. In these bins, residents pour all recyclable materials. Once collected by RFID-equipped collection trucks, the customer's account is credited for the weight of the contents in the cart [36]. The amount of material recycled is converted into RecycleBank Points, which can use at participating reward partners. These include national and local retailers such as:

- Bed, Bath \& Beyond

- CVS/pharmacy

- Dick's Sporting Goods

- Foot Locker

- Home Depot

- Petco.com

- Rite-Aid

- Sears

- Starbucks

- $\quad$ Target.com [37].

The recyclable materials - paper, plastics, cardboard, aluminum, etc. - are then separated at processing centers. After being separated by type, the material can then be directed towards reuse [37]. 
What are the results? Ron Gonen, RecycleBank's cofounder and CEO, reports that the benefits of incentivizing the recycling behaviors of individuals can make whole cities much greener. In fact, Gonen reports that: "We've taken cities with almost no recycling and brought them to 40 percent of their trash being diverted from waste" [35]. For municipalities and waste haulers, this means that rather than having to pay the rising tipping fees for delivering MSW to landfills, they can actually reverse the equation, earning money on the volume of waste products that are directed towards recycling [4]. For the customer, RecycleBank provides incentive credits based on their actual recycling volume, offering discounts and credits at hundreds of retail partners, ranging from the national brands (listed previously) to local retailers, restaurants and grocery stores. Kraft Foods is one of the lead sponsors of RecycleBank, offering discounts on its family of products as incentives for consumer recycling. Kraft's Elisabeth Wenner, the firm's director of sustainability, says that the value proposition for her company is that by encouraging recycling, Kraft helps reduce the amount of its own and others' product packaging in landfills. Thus, according to Wenner, "RecycleBank offers an innovative way to make it easy and rewarding for consumers to recycle" [35]. For corporate partners, the RecycleBank incentive program offers a marketing tool to encourage both first use of their products or services and to promote repeat transactions. Thus, they are a way of "doing well by doing good," promoting both individual and corporate environmental responsibility - and a unique marketing program at the same time.

\section{Analysis}

All in all, the Municipal Solid Waste market holds the potential for rapid development over the next few years for RFID solutions providers, as well as those vendors providing the hardware and software necessary to support PAYT and for monitoring recycling. In fact, today's economic conditions could work to benefit solutions providers in this area by accelerating the growth of both the PATY and recycling incentive programs, both in the U.S. and abroad. This is evidenced by the growing interest in such programs across Europe [33, 35]. Likewise, the concern over the impact of MSW on climate change could also work to spur the growth of both PAYT and greater recycling efforts [38]. This is evidenced by the rapid growth of an incentivebased recycling program in Michigan. Introduced by a start-up firm, Rewards for Recycling, the company has enlisted over 80,000 households across several counties in Michigan in just its first six months of operations [39]! Thus, the curbside may be one of the most promising areas for RFID technology to be employed, not just for profits, but for a greener world as well. In industry after industry, RFID has proven to be a transformative, game-changing technology, producing new levels of efficiency, customer service and business intelligence. We should expect no less in the world of trash, in order to minimize the amount of trash and maximize the health of the planet.

\section{REFERENCES}

[1] U.S. Environmental Protection Agency (EPA), Municipal solid waste generation, recycling, and disposal in the United States: Facts and figures for 2007 (Released November 2008). [Online]. Available: http://www.epa.gov/epawaste/nonhaz/municipal/pubs/msw07-fs.pdf [Accessed: December 10, 2008].

[2] C. Wang, M. Lin and C. Lin, "Factors influencing regional municipal solid waste management Strategies.” Journal of the Air \& Waste Management Association, 58(7), July 1, 2008. [Online]. Available: http://www.highbeam.com/doc/1G1-181856762.html [Accessed: January 2, 2009].

[3] National Solid Wastes Management Association, White paper: Modern landfills - A far cry from the past, [Online]. Available: 
http://wastec.isproductions.net/webmodules/webarticles/articlefiles/463white\%20paper\%20landfill\%20final.pdf [Accessed: November 15, 2008].

[4] K. Abbott, White paper: The economics of recycling (Released September 2008). [Online]. Available: http://recyclebank.com/recycling/economics [Accessed: November 20, 2008].

[5] P. Portney and R.N. Stavins, Public policies for environmental protection. Washington, DC: RFF Press, 2000.

[6] M. Chee, "Tracking the trash: Avatar Partners' RFID solution adds efficiency and accuracy to Allied Waste's Disposal Services.” RFID Product News, Spring 2008. [Online]. Available: http://www.rfidproductnews.com/issues/2008.06/cover.story.php [Accessed: December 30, 2008].

[7] World Wildlife Fund, Municipal Solid Waste Factsheet - 2008. [Online]. Available: http://www.wwfpak.org/factsheets_mswf.php [Accessed: January 13, 2009].

[8] S. d'Hont, The cutting edge of RFID technology and applications for manufacturing and distribution: A white paper from Texas Instruments (Released July 2003). [Online]. Available: http://www.ti.com/tiris/docs/manuals/whtPapers/manuf dist.pdf [Accessed: April 23, 2004].

[9] R. Malone, "Reconsidering the role of RFID." Inbound Logistics, August 2004. [Online]. Available: http://www.inboundlogistics.com/articles/supplychain/sct0804.shtml [Accessed: September 18, 2004].

[10] D.C. Wyld, RFID: The right frequency for government - A research report from The IBM Center for the Business of Government, September 2005. [Online]. Available: http://www.businessofgovernment.org/main/publications/grant_reports/details/index.asp?gid=23 2 [Accessed: October 3, 2005].

[11] R. Singel, "American passports to get chipped." Wired, October 21, 2004. [Online]. Available: http://www.wired.com/news/privacy/0,1848,65412,00.html [Accessed: December 2, 2004].

[12] J. Van, "RFID spells media revolution, futurist says." Chicago Tribune, 24(104), p. B1, April 16, 2005.

[13] D.C. Wyld, "RFID 101: The next big thing for management." The Engineering Management Review, Vol. 35, No. 2, pp. 3-19, May 2007.

[14] D.C. Wyld, "The implant solution: Why RFID is the answer in the highly unique orthopedic supply chain, providing ROI for suppliers and assurance for patients and their surgeons." ID World, Issue 15, pp. 12-15, June 2008.

[15] D.C. Wyld, "Playing a deadly game of match: How new efforts to use RFID in blood banking and transfusion can save patient lives and safeguard the blood supply chain." Global Identification, Issue 37, pp. 24-26, March 2008.

[16] D.C. Wyld, "The importance of pedigree: Why instituting RFID-based tracking of pharmaceuticals is essential to counteracting counterfeiting and maintaining both the health of the public and the potency of the American drug industry." Competition Forum, 4(1), pp. 261266, October 2006.

[17] D.C. Wyld, "Sports 2.0: A look at the future of sports in the context of RFID's 'Weird New Media Revolution."' The Sport Journal, 9(4), pp. 3-17, December 2006.

[18] D.C. Wyld, "DaVinci uncoded: RFID is enhancing the management and experience of art galleries and museums... and even becoming a part of the artists' palettes for creating works of art." Global Identification, Issue 26, pp. 36-40, May 2006.

[19] D.C. Wyld, "Radio frequency identification: Advanced intelligence for table games in casinos," Cornell Hospitality Quarterly, Vol. 49, No. 2, pp. 134-144, June 2008.

[20] J.L. Canterbury, "Pay-as-you-throw: The Bonus Beyond Waste Prevention." Waste Age, May 1,1996. [Online]. Available http://wasteage.com/mag/waste_payasyouthrow_bonus_beyond/.[Accessed: November 16, 2008]. 
[21] P. Tracy, "Waste Management (WMI) turns trash into nearly $\$ 1.2$ billion in cash a year." Street Authority Market Advisor, April 21, 2008. [Online]. Available: http://www.topstockanalysts.com/cmnts/2008/04-21-waste-management.asp [Accessed: July 18, 2008].

[22] U.S. Environmental Protection Agency (EPA), Pay-as-you-throw (Released September 2008). [Online]. Available: http://www.epa.gov/osw/conserve/tools/payt/ [Accessed: December 12, 2008].

[23] U.S. Conference of Mayors, A primer on variable rate pricing for solid waste services. Washington, DC: The United States Conference of Mayors, 1994.

[24] J. Sorensen, White paper: More airlines worldwide choosing revenue-based methods to serve and reward customers (Issued December 1, 2008). [Online]. Available: http://www.ideaworkscompany.com/press/2008/AnalysisRevenueBased2008.pdf [Accessed: June 17, 2009].

[25] J. Thogersen, "Monetary incentives and environmental concern: Effects of a differentiated garbage fee," Journal of Consumer Policy, 17(4), pp. 407-442, December 1994.

[26] U.S. Environmental Protection Agency (EPA), General public - Throw away less and save (Released April 1997). [Online]. Available: http://www.epa.gov/osw/conserve/tools/payt/tools/public.htm [Accessed: December 12, 2008].

[27] P. Moriarty, "Financing waste collection for maximum diversion." BioCycle, 35(1), pp. 15-18, January 1994.

[28] G. Harder and L. Knox, "Implementing variable trash collection rates. BioCycle, 33(4), pp. 1831, April 1992.

[29] C.M. Villa and A.J. Chua, "Dirty talk - Paying for trash. PAYT in the Philippines: Issues and concerns." Business World Online, January 1, 2009. [Online]. Available: http://www.bworldonline.com/Features_2008/content.php?id=IDEA010109 [Accessed: August $16,2009]$.

[30] D. Fullerton and T.C. Kinnaman, "Household responses for pricing garbage by the bag." American Economic Review, 86(4), pp.971-984, November 1996.

[31] J. Wyatt, "Maximizing waste management efficiency using RFID." RFID Product News, Fall 2008. [Online]. Available: http://www.rfidproductnews.com/issues/fall2008/waste.php. . [Accessed: September 15, 2009].

[32] J. Wyatt, "RFID waste management: Pay-as-you-throw.” RFID World, November 10, 2008. [Online]. Available: http://www.rfid-world.com/showArticle.jhtml?articleID=212001679 [Accessed: September 15, 2009].

[33] F.M. Lansana, "A comparative analysis of curbside recycling behavior in urban and suburban communities.” The Professional Geographer, 45(2), pp. 169-179, June 2005.

[34] Anonymous, “Irish Company's RFID Waste Management Technology Comes to the United States." American Recycler, November 2008. [Online]. Available: http://www.americanrecycler.com/1108/irish.shtml. [Accessed: October 1, 2009].

[35] M.C. O'Connor, "Routeware launches RFID solution for waste haulers: The system employs low-frequency RFID interrogators on trash-collection trucks to identify tagged waste and recycling containers, as well as track the recycling efforts of the residents they serve." RFID Journal, May 5, 2008. [Online]. Available: http://www.rfidjournal.com/article/articleprint/4067/-1/1/ [Accessed: February 15, 2009].

[36] C. Swedberg, "RFID helps reward consumers for recycling: Kraft Foods joins RecycleBank in its use of RFID to track and reward consumers for recycling." RFID Journal, February 22, 2008. [Online]. Available: http://www.rfidjournal.com/article/articleprint/3936/-1/1/ [Accessed: June $11,2009]$.

[37] A. Crowe, "RecycleBank is the eco-friendly way to cash in your trash." Boston Happenings Examiner, January 10, 2009. [Online]. Available: http://www.examiner.com/x-1987-Boston- 
Happenings-Examiner y2009m1d10-RecycleBank-helps-you-cash-in-for-doing-good [Accessed: June 27, 2009].

[38] U.S. Environmental Protection Agency (EPA), Fact sheet: Climate change and municipal solid Waste (MSW) (Released September 2008). [Online]. Available:

http://www.epa.gov/osw/conserve/tools/payt/tools/factfin.htm [Accessed: June 20, 2009].

[39] M.C. O'Connor, "Michigan households get RFID-enabled rewards for recycling." RFID Journal, October 9, 2009. [Online]. Available: http://www.rfidjournal.com/article/view/5293/ [Accessed: October 28, 2009].

Author

David C. Wyld (dwyld@ selu.edu) currently serves as the Robert Maurin Professor of Management at Southeastern Louisiana University in Hammond, Louisiana. He is the Director of the College of Business' Strategic e-Commerce/e-Government Initiative, the Founding Editor of both the Journal of Strategic e-Commerce and the International Journal of International Journal of Managing Information Technology (current editor). He is a frequent contributor to both academic journals and trade publications. He has established himself as one of the leading academic experts on emerging applications of technology in both the public and private sector. He has been an active consultant, a qualified expert witness, and an invited speaker on the strategic management of technology to both trade and academic audiences.

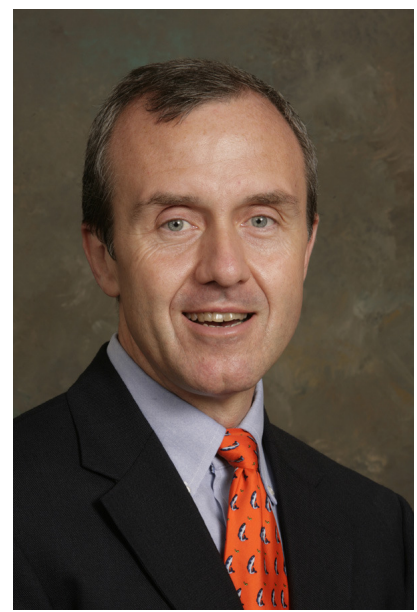

